\title{
Synthesis and Properties of High Strength Thin Film Composites of Poly(ethylene Oxide) and PEO-PMMA Blend with Cetylpyridinium Chloride Modified Clay
}

\author{
Mohammad Saleem Khan ${ }^{1}$ and Sabiha Sultana,2 \\ ${ }^{1}$ National Centre of Excellence in Physical Chemistry, University of Peshawar, Peshawar 25120, Pakistan \\ ${ }^{2}$ Government College Women University, Madina Town, Faisalabad 3800, Pakistan
}

Correspondence should be addressed to Mohammad Saleem Khan; saleemkhan@upesh.edu.pk

Received 25 March 2015; Revised 21 May 2015; Accepted 24 May 2015

Academic Editor: Beng T. Poh

Copyright (C) 2015 M. S. Khan and S. Sultana. This is an open access article distributed under the Creative Commons Attribution License, which permits unrestricted use, distribution, and reproduction in any medium, provided the original work is properly cited.

Ion-conducting thin film composites of polymer electrolytes were prepared by mixing high MW poly(ethylene oxide) (PEO), poly(methyl methacrylate) (PMMA) as a polymer matrix, cetylpyridinium chloride (CPC) modified MMT as filler, and different content of $\mathrm{LiClO}_{4}$ by using solution cast method. The crystallinity, ionic conductivity $(\sigma)$, and mechanical properties of the composite electrolytes and blend composites were evaluated by using XRD, AC impedance, and UTM studies, respectively. The modification of clay by CPC showed enhancement in the $d$-spacing. The loading of clay has effect on crystallinity of PEO systems. Blend composites showed better mechanical properties. Young's modulus and elongation at break values showed increase with salt and clay incorporation in pure PEO. The optimum composition composite of PEO with $3.5 \mathrm{wt} \%$ of salt and $3.3 \mathrm{wt} \%$ of CPMMT exhibited better performance.

\section{Introduction}

Polymer/clay composites are hybrid materials which contain organically modified clay and polymer matrix. These are extensively studied materials because of enhanced mechanical, thermal, optical, and other properties. The availability of clay, its low cost, and well developed intercalation chemistry have added to attracting researchers towards material preparation from this. Polymer molecules are believed to intercalate into the galleries of the clay [1]. The amount of clay in these composites plays a vital role in affecting polymer crystallinity and mechanical properties. Pure nonmodified clay is difficult to intercalate and disperse homogeneously in the polymer matrix because of high interfacial tension with organic materials. To overcome this problem, clay is modified to introduce hydrophobic character in it making intercalation with polymers possible. Organic modifier, nature of polymer, and processing conditions are major factors that affect the structure of the resulting composite. It has been indicated that the functional groups and chain length of the backbone of organic modifier have vital influence on the $d$-spacing and elastic modulus of the polymer-clay composites and crystallinity of polymers [1]. Keeping this in mind, the selection of polymer and organic modification of clay is very important factor in preparation and use of such polymer-clay composite.

It is a well-known fact that poly(ethylene oxide) (PEO) is a unique polymer soluble in both aqueous and organic solvents. It has polyether chain which can coordinate with alkali cations $\left(\mathrm{Li}^{+}, \mathrm{Na}^{+}, \mathrm{Ca}^{2+}\right.$, etc.) resulting in the formation of polyelectrolyte for batteries, supercapacitors, and fuel cells [2-4]. PEO based polyelectrolytes have been found to show low conductivity while their blend with other polymers and incorporation of salts show enhancement in conductivity [5]. The incorporation of clay having silicate layer is also known to increase the conductivity of PEO based electrolytes. The composite of $\mathrm{PEO} / \mathrm{Clay}$ has been studied in detail from time to time [6-9]. Most of the work so far has been done on composite containing only PEO-Clay. On the other hand, to our knowledge there are no/or a few reports of PEO-PMMA 
blend clay composites $[10,11]$ and also the cetylpyridinium chloride modified montmorillonite clay (CPMMT) has not been used to prepare such composites. The present work aims at the synthesis and characterization of PEO-PMMA/Clay composite with $\mathrm{LiClO}_{4}$ salt using cetylpyridinium chloride modified montmorillonite clay. The detailed X-ray diffraction, electrical, and mechanical properties have been investigated and discussed in the present work. Further thin film fabrication of these composites which has not been reported earlier has been done and reported here. This type of thin film configuration may find application not only in solid polymer electrolyte but also in shape memory polymers for improved mechanical properties.

\section{Experimental}

2.1. Materials. Poly(ethylene oxide) (PEO) (MW 600,000) and poly(methyl methacrylate) (PMMA) (high molecular weight) were obtained from Acros and $\mathrm{BDH}$ Chemicals, respectively. The clay, montmorillonite, was purchased from Aldrich Chemicals. Research grade lithium perchlorate $\mathrm{LiClO}_{4}$ (MW106.39) was obtained from Acros Chemicals. All these polymers and chemicals were used as such without further purification. Acetonitrile $\left(\mathrm{CH}_{3} \mathrm{CN}\right)$ was used as a solvent. It is a good solvent for polymers, that is, PEO and PMMA, montmorillonite, and salts.

\subsection{Methods}

2.2.1. Modification of Clay. One drawback to clay minerals for battery electrolytes is their hydrophilic nature. Cation modification is one way to avoid this issue. Researchers are exploring organic cation and their ability to make hydrophilic clays into organophilic compounds. The term organic implies that organically modified clays can be attached to organic polymers. The organic modification of clay in our system was carried out according to the procedure reported earlier in the literature [12].

2.2.2. Preparation of PEO/Salt/CPMMT and PEO/PMMA/ Salt/CPMMT Composite Films. PEO and PMMA were dissolved separately in acetonitrile to prepare $2 \%$ solution. Constant volume of this $2 \%$ polymer solution was mixed with different volumes of $1 \mathrm{M} \mathrm{LiClO}_{4}$ and CPMMT, following continuous stirring for $24 \mathrm{~h}$ at $60^{\circ} \mathrm{C}$. These solutions were then transferred to Petri dishes of uniform diameter, kept on smooth and leveled surfaces, covered with lids and were left at room temperature for drying and converting into uniform smooth films of PEO/CPMMT (3.3 wt\%)/Salt (2.1, 3.5, and $5 \mathrm{wt} \%)$ and PEO/PMMA/CPMMT (3.3 wt\%)/Salt (2.1, 3.5, and $5 \mathrm{wt} \%$ ) polymeric composites designated as PCS2.1, PCS3.5, PCS5, PPCS2.1, PPCS3.5, and PPCS5, respectively. The films obtained were stable and free standing.

2.3. Instrumentation. The X-ray diffractometry (XRD) was carried out by using $\mathrm{Cu}-\mathrm{k} \alpha$ radiation at a tube voltage of $40 \mathrm{KV}$ and $20 \mathrm{~mA}$ current. Rigaku (Japan) FX Geiger Series RAD_B system was used for X-ray diffraction measurements.
TABLE 1: Values of $d$-spacing for various systems studied.

\begin{tabular}{lcc}
\hline System & $\begin{array}{c}\text { Peak position* } \\
(2 \theta)\end{array}$ & $d$-spacing \\
\hline MMT & 11.65 & 7.5839 \\
CPMMT & 11.30 & 7.8266 \\
PEO/CPMMT/Salt (2.1wt\%) & 22.95 & 3.8720 \\
PEO/PCPMMT/Salt (2.1 wt\%) & 22.85 & 3.8090 \\
\hline
\end{tabular}

${ }^{*}$ Peak with highest intensity.

The tensile properties of the samples were tested using Testometric universal testing machine M350/500 manufactured by Testometric UK. The films of pure polymers and that of selected compositions of composites with uniform thickness (measured with digital micrometer) and width were cut for analysis. The length of each sample was $50 \mathrm{~mm}$. The analysis was performed at room temperature with cross-head speed of $5 \mathrm{~mm} / \mathrm{min}$. For high accuracy and precision, a sensitive load cell of $100 \mathrm{~kg}$ capacities with $1.0 \mathrm{mg}$ load detection with a minimum $0.01 \mathrm{~mm}$ cross-head speed was used. A special griping system was designed for thin film griping to avoid any slippage during tensile test. Standard procedure and formulae were used for calculating various tensile properties including Young modulus (stiffness) and elongation at break. Data directly feed into computer interfaced with the UTM.

The impedance measurements were carried out at room temperature $\left(15^{\circ} \mathrm{C}\right)$ using Solartron 1260 frequency response analyzer (FRA) over the frequency range of $1-1 \times 10^{7} \mathrm{~Hz}$ and $100 \mathrm{mv}$ voltage. The impedance data were then transferred to the (Z-plot/Z-view) software package.

\section{Results and Discussion}

Montmorillonite clay (MMT) clay structure along with CPC structure is shown in Figure 1. The structure shows that an octahedrally coordinated alumina is sandwiched between two tetrahedrally coordinated silica. The spacing between clay layers ranges in nanometers and in between these layers water molecules and exchangeable cations like $\mathrm{Na}^{+}$are present. These $+\mathrm{Ve}$ ions are mostly near the layers where the -Ve site of the layer is present and a kind of attachment is there between these. The CPC has a bulky cationic head and hydrocarbon chain which is neutral. The MMT clay was modified with cetylpyridinium chloride (CPC) whose structure is shown in Figure 2. The mechanism clearly shows that smaller $\mathrm{Na}^{+}$is exchanged with the bulky cationic head group of $\mathrm{CPC}$ while $\mathrm{NaCl}$ is coming out after treatment. Due to this exchange and insertion of larger cation in between layers, the interlayer spacing increases (see Table 1). The modified clay, that is, CPMMT, is organophilic with a lower surface energy, which is more compatible with organic polymers.

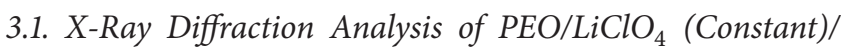
CPMMT Composite System. XRD of pure PEO shows maximum diffraction peaks representing highly crystalline structure as already published in our earlier studies [13]. $\mathrm{LiClO}_{4}$ 

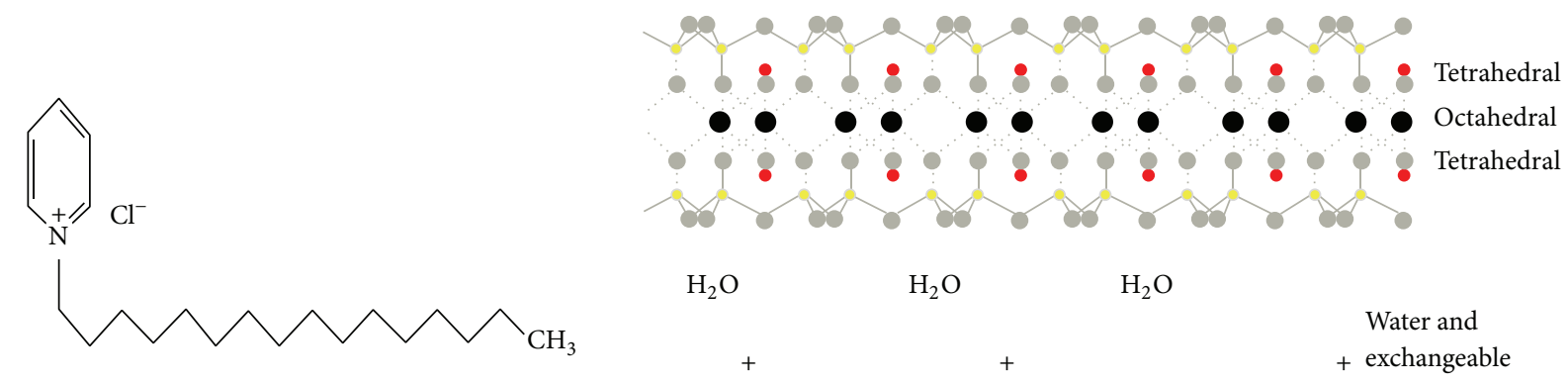
Water and
+ exchangeable cations
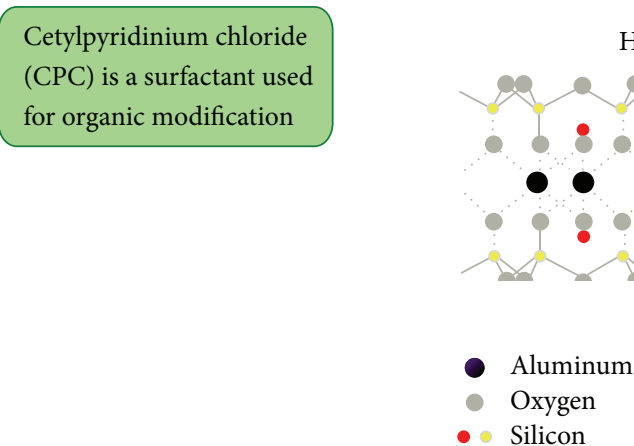

FIgURE 1: Structure of MMT clay and CPC.

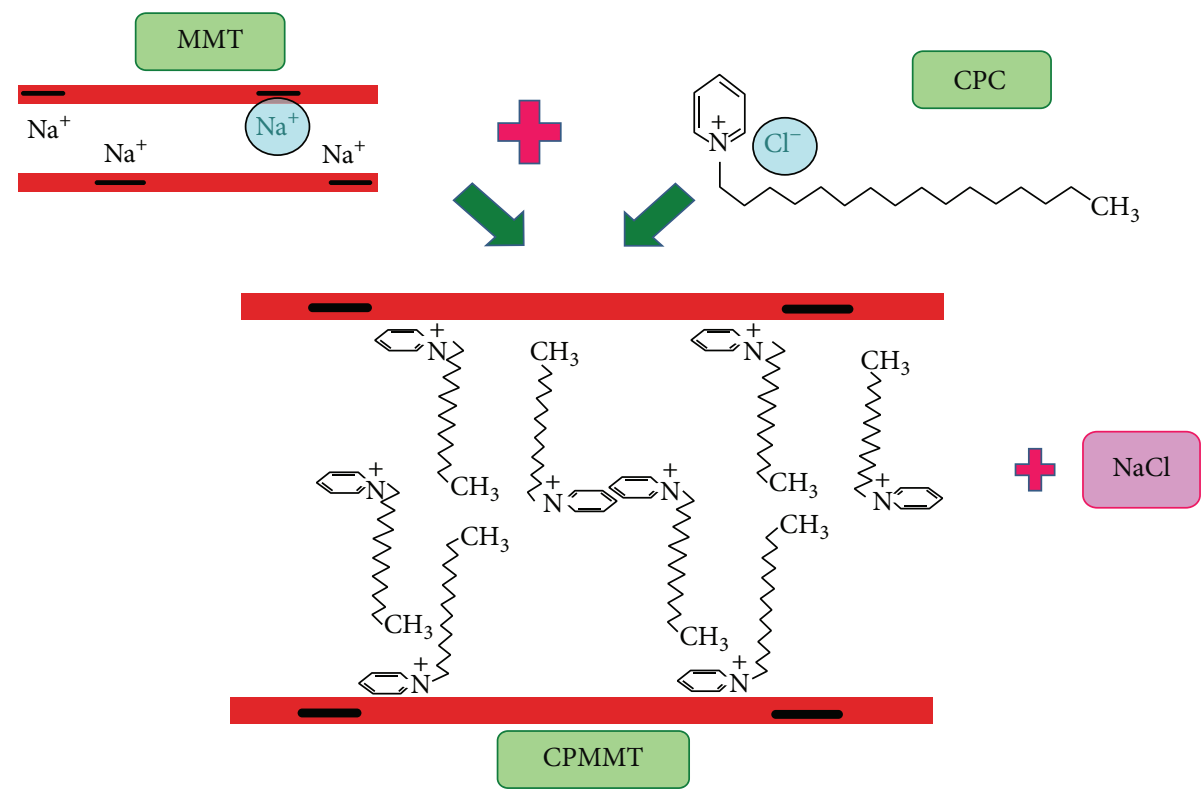

FIGURE 2: Mechanism of modification of MMT.

$\mathrm{XRD}$ was not done but, as reported in literature, $\mathrm{XRD}$ pattern of $\mathrm{LiClO}_{4}$ shows intense peaks at angle $2 \theta=18.360,23.20$, $27.50,32.990$, and 36.580 revealing the crystalline nature of the ionic salt [14]. Figures 3 and 4 display the XRD scan of pure and CPC modified MMT, respectively. It is clear from the diffractogram and Table 1 that modification of clay by CPC enhances the $d$-value from 7.5839 to 7.82366 by shifting $2 \theta$ value from 11.65 to 11.30 . It also shows the addition of new peaks at $2 \theta=17.75$ and 55.3 and vanishing of some peaks at $2 \theta=20.8,42.4,50.15$, and 54.3. The addition and disappearance of peaks and alteration of $d$-values clearly depict the successful modification of montmorillonite by CPC. The rest of the peaks are not altered. The increasing $d$-spacing will cause the dissociation of MMT, resulting in composites with better dispersion of clay particles [15].

The polymer/salt/CPC modified structure and interaction mechanism is given in Figure 5. The interaction of CPMMT with polymer (PEO) shows that polymer molecules come in between the CPC layers attached to clay. An elaboration of the intercalating portion clearly shows that there is 


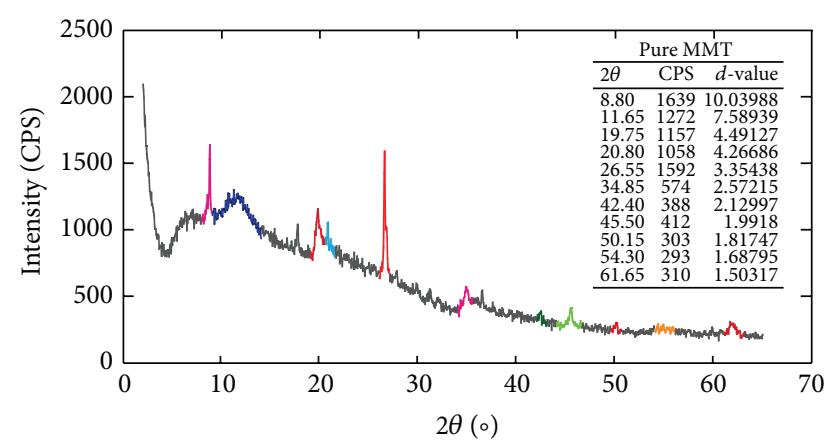

FIgURE 3: XRD scan of pure MMT.

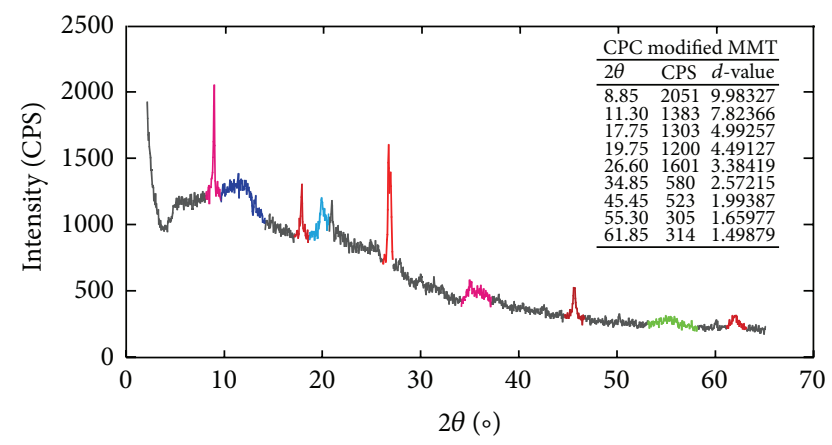

FIGURE 4: XRD scan of CPMMT.

increase in gallery spacing which is associated with lowering in surface energy. Polymer intercalates within the galleries as a result of the negative surface charge and the cationic head groups of CPC preferentially reside on the layer surface. The salt, that is, $\mathrm{LiClO}_{4}$ has also interactions with both the polymer and the negatively charged clay layers.

Composites of $\mathrm{PEO} / \mathrm{LiClO}_{4} / \mathrm{CPMMT}$ were synthesized with $1.98,3.3,4.62$, and $5.94 \mathrm{wt} \%$ of modified montmorillonite loading keeping the mole fraction of salt constant at $3.5 \mathrm{wt} \%$. The diffraction patterns of PEO/Salt/CPMMT (1.98 (A), 3.3 (B), 4.62 (C), and 5.94 (D) wt\%) composite systems are shown in Figure 6. It can be revealed from these XRD patterns that the PEO has the minimum crystallinity when the CPMMT loading is $3.3 \mathrm{wt} \%$. This $3.3 \mathrm{wt} \%$ of CPMMT loading was selected as an optimum condition for the synthesis of the composites. The substantial increase in the intensities of the XRD peaks on increasing CPMMT loadings suggests that the dispersion is better at lower clay loading than at higher loadings. This is because the lithium cation coordinates with the flexible $\mathrm{CH}_{2}-\mathrm{O}$ - chain of PEO forming complexes and thereby disturbing the crystallinity. When the clay is loaded into the $\mathrm{PEO} / \mathrm{Li} \mathrm{ClO}_{4}$ electrolyte the crystallinity initially decreases up to $3.3 \mathrm{wt} \%$ of clay loading and increases thereafter. In case of undoped PEO, the crystallinity gradually decreases with an increase in clay loading because of the steric hindrance caused by the huge surface area of randomly oriented clay throughout the matrix. The different crystallization behaviors of $\mathrm{PEO} / \mathrm{LiClO}_{4} /$ clay composite electrolyte and PEO/Clay composite is explained by considering the fact that negatively charged clay layers also coordinate with the lithium cation due to a strong electrostatic interaction. The interaction depends on the expansion of silicate layers and clay content. Because of this interaction, $\mathrm{PEO}$ to $\mathrm{Li}^{+}$interactions decrease and crystallinity increases. Thus two competing effects are present in the $\mathrm{PEO} / \mathrm{LiClO}_{4} /$ Clay composite electrolyte; one reduces the crystallinity and the other favors the crystallinity. At low clay loading the first factor predominates leading to a decrease in the crystallinity and beyond the optimum clay concentrations the second factor predominates over the first, resulting in higher crystallinity [16, 17]. The presence of the CPMMT, however, had no effect on the location of the peaks, which indicates that perfect exfoliation of the clay layer structure of the organoclay in PEO does not occur [18]. The XRD patterns of the fabricated composites show that most of the peaks corresponding to pure $\mathrm{LiClO}_{4}$ have disappeared in the composite system, which reveals the dissolution of the salt in the polymer matrix. Similarly the appearance of some of the peaks of the $\mathrm{LiClO}_{4}$ in the composite system confirms the complexation of the salt with the polymer matrix.

3.2. X-Ray Diffraction Analysis of $\mathrm{PEO} / \mathrm{LiClO}_{4}$ (Variable)/ CPMMT (3.3 wt\%) Composite System. X-ray diffraction analysis of $\mathrm{PEO} / \mathrm{LiClO}_{4} / \mathrm{CPMMT}$ composite with $3.3 \mathrm{wt} \%$ of CPMMT clay at varying concentrations of salt is shown in Figure 7 , which depicts that $\mathrm{PEO} / \mathrm{LiClO}_{4} /$ clay composites first show decrease in crystallinity of PEO with the increasing amount of salt, but when the concentration of salt is increased from PCS2, that is, $3.5 \mathrm{wt} \%$, the crystalline character of PEO starts increasing; this is attributed to the local aggregation of inorganic particles at higher salt concentration. The same result is manifested by our mechanical and Scanning Electron Microscopy (SEM) studies.

3.3. X-Ray Diffraction Analysis of PEO/PMMA/LiClO ${ }_{4}$ (Variable)/CPMMT (3.3wt\%) Blend Composite System. In order to investigate the effect of poly(methyl methacrylate) (PMMA) addition on the crystallinity of PEO in the blend composite of $\mathrm{PEO} / \mathrm{PMMA} / \mathrm{LiClO}_{4} / \mathrm{CPMMT}$ having variable concentrations of salt and constant clay content (of $3.3 \mathrm{wt} \%$ ), X-ray analysis was carried out. From the diffractogram pattern given in Figure 8, it is clear that though PMMA is amorphous in nature, its addition to the composite system has no significant effect on the system. The crystalline fraction of PEO increased a little bit by its addition. This is because the amount of PEO in PEO/PMMA blend is far more than overlap weight fraction $\left(W^{*}\right)$, which causes PEO to crystallize, and also because PMMA interaction with CPMMT is more than that of PEO which affects the properties of PEO when present in blend. The $d$-spacing between the layers of the system is found to be decreasing (Table 1) which also accounts for increase of crystalline behavior. This result is consistent with our AC impedance study and is also supported by the literature [18].

\subsection{Ionic Conductivity of PEO Composite and Blend Compos-} ite System. In a Nyquist impedance plot, the real part $\left(Z^{\prime}\right)$ of the impedance was plotted against the imaginary part $\left(Z^{/ /}\right)$ for data collected at frequencies ranging from 1 to $10^{7} \mathrm{~Hz}$. 


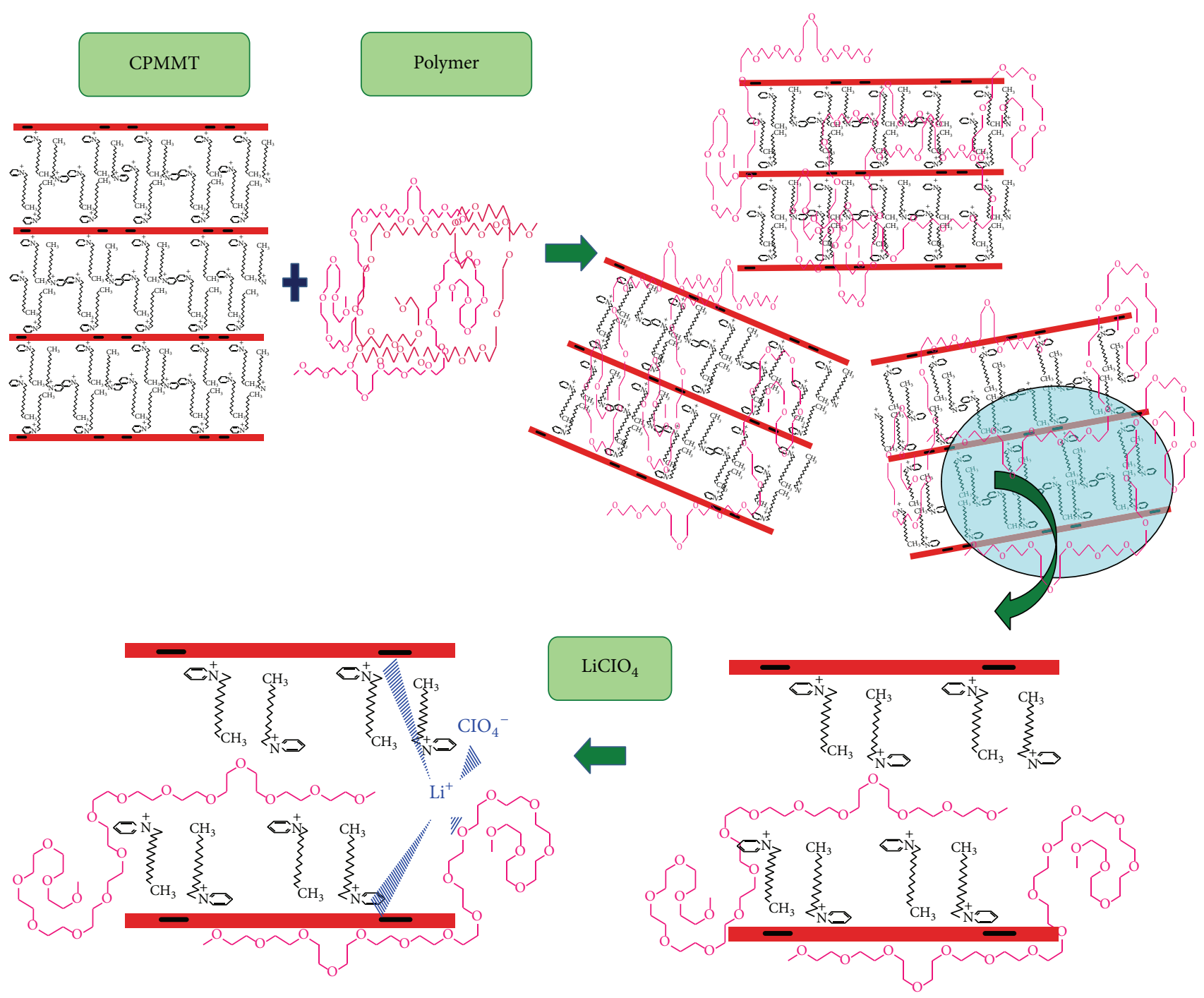

FIGURE 5: Mechanism of PEO-Salt/CPMMT interaction.

To investigate complete picture of the system, an equivalent circuit was used [19]. The bulk resistance of the solid polymer electrolyte (SPE) was consequent from the equivalent circuit. Figures 9(a), 9(b), 9(c), and 9(d) show the Nyquist impedance plots for $\mathrm{PEO} / \mathrm{LiClO}_{4}$, denoted as PS (a), $\mathrm{PEO} / \mathrm{LiClO}_{4}$ after fitting to equivalent circuit (b), $\mathrm{PEO} / \mathrm{CPMMT} / \mathrm{LiClO}_{4}$ denoted as PCS (c), PEO/PMMA/CPMMT/LiClO 4 denoted as PPCS (d), and impedance plot after fitting to the equivalent circuit, respectively. These diagrams deviate from an ideal impedance spectrum that usually exhibits a standard semicircle at the high frequency section and a vertical line at a lower frequency section. The deformed semicircle and the inclined line for the polymeric film/electrode system may be attributed to the irregular thickness and morphology of the polymeric film and the roughness of the electrode surface $[20,21]$. To investigate the phenomenon a "constant phase element" (CPE) was employed in the equivalent circuit. The high frequency semicircle depicts the combination of R1 and CPE-1, while the spike showing the trend for second semicircle due to double layer capacitance (at the interface of solid polymer electrolyte and electrode) is reflected by CPE2 [19]. The equivalent circuit used for fitting data and table for parameters for the circuit elements evaluated by fitting the impedance data for composite and blend system at room temperature $\left(15^{\circ} \mathrm{C}\right)$ is given in Figure 9 as inset.

From equivalent circuits the bulk resistance values were obtained. The bulk resistance allows us to obtain the ionic conductivity using

$$
\sigma=\frac{I}{R A}
$$

where $\sigma=$ conductivity $(\mathrm{S} / \mathrm{cm}), R=$ resistance $(\Omega), I=$ thickness $(\mathrm{cm})$, and $A=$ area of the electrode $\left(\mathrm{cm}^{2}\right)$.

The capacitance values were calculated according to

$$
\omega_{\max R C=1},
$$

where $\omega_{\max }$ corresponds to the frequency at the maximum of semicircle. The capacitance values obtained for the bulk are in complete harmony with the earlier reported values [22]. 


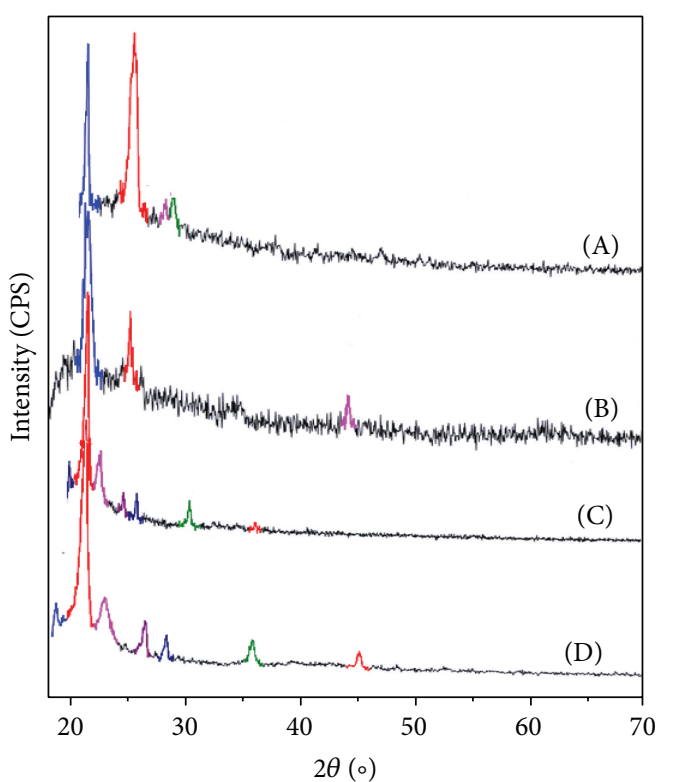

FIgURE 6: Combined XRD pattern of PEO/Salt composite system with 1.98 (A), 3.3 (B), 4.62 (C), and 5.94 (D) wt\% of CPMMT.

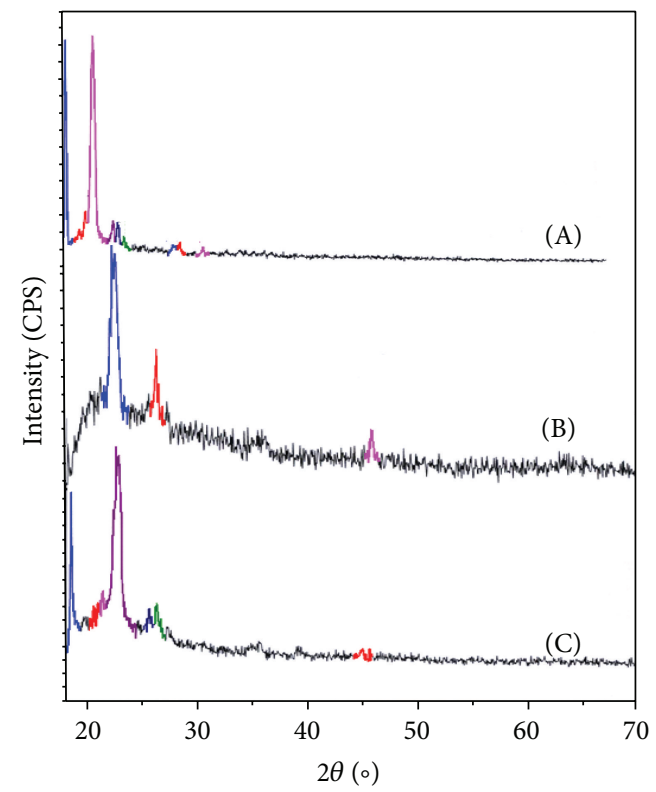

FIgURE 7: Combined XRD scans of PEO/CPMMT/Salt (PCS1) (2.1 wt\% A), PEO/CPMMT/Salt (PCS2) (3.5 wt\% B), and $\mathrm{PEO/}$ CPMMT/Salt (PCS3) (5 wt\% C).

The value of ionic conductivity obtained at room temperature $\left(15^{\circ} \mathrm{C}\right)$ for pure poly(ethylene oxide) (PEO) is less than $6.78 \times 10^{-10} \mathrm{~S} \mathrm{~cm}^{-1}$ reported in the literature earlier by Kumar and coworker [17] for the same molecular weight PEO at $30^{\circ} \mathrm{C}$. This difference in conductivity values is because of the temperature and changing nature of solvent used in our study [23]. From the table given as inset in Figure 10, it is clear that the conductivity of PEO at laboratory temperature, that is, $15^{\circ} \mathrm{C}$, increases sharply with the salt incorporation. The

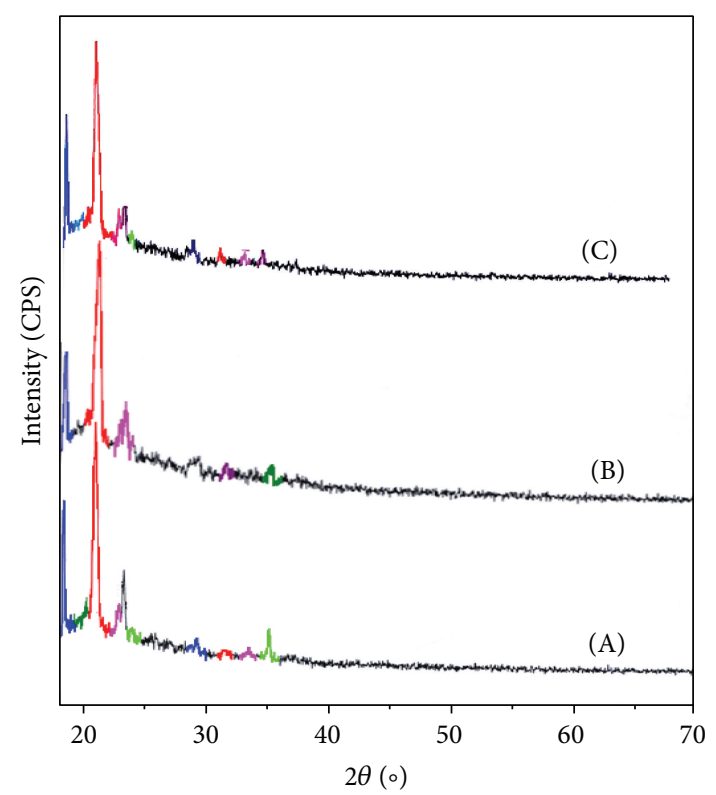

Figure 8: Combined XRD scans of PEO/PMMA/CPMMT/Salt (PPCS1) (2.1 wt\% A), PEO/PMMA/CPMMT/Salt (PPCS2) (3.5 wt $\%$ $\mathrm{B})$, and PEO/PMMA/CPMMT/Salt (PPCS3) (5 wt\% C).

same trend in conductivity of PEO based electrolytes with the salt concentration has also been observed by Srivastava and Ibrahim et al. $[24,25]$. This increase is due to the increase in charge carriers caused by the addition of higher concentration of $\mathrm{LiClO}_{4}$ and the increase in the fraction of amorphous phase. The addition of ionic salt decreases degradation temperature because of the growth of amorphous fraction and destabilizes the polymer network. The $\mathrm{PEO} / \mathrm{LiClO}_{4}$ electrolyte with high salt concentration was found to be less stable. Alternatively CPMMT was used to overcome these drawbacks. Inorganic fillers are usually used to improve the electrochemical and mechanical properties [26]. Clay is inorganic filler with intercalation property, where clay layers maintain their registry. Intercalating polymer (residing polymer chains between silicates) in a layered clay host can produce huge interfacial area to sustain the mechanical property of polymer electrolyte system and impart salt solvating power to dissolve the lithium salt [27]. A glance at Figure 10 and inset table reveals that the addition of salt at constant $(3.3 \mathrm{wt} \%)$ clay content increases the conductivity of PEO/Salt/CPMMT (PCS) composites retaining dimensional stability till PCS2 (3.5 wt\%); beyond PCS2, further addition of salt decreases the conductivity badly. This initial increase is due to the decrease in the crystallinity and increase in amorphous fraction of PEO for ion conduction till equilibrium is achieved at PCS2. This is consistent with our XRD results. The conductivity decreases drastically, when amount of salt increases from PCS2 to PCS3 (5 wt\%), but is still higher than that of pristine polymer. The possible explanation for this behavior may be ion association and the formation of charge multipliers [25]. In order to study the effect of poly(methyl methacrylate) (PMMA) incorporation on the ionic conductivity of PEO based solid polymer electrolytes, PMMA was blended with 


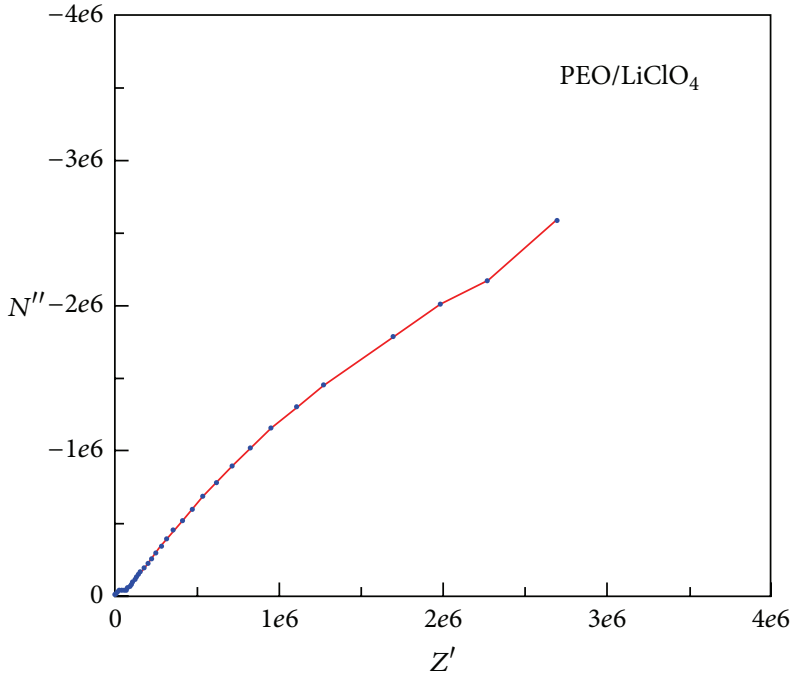

(a)

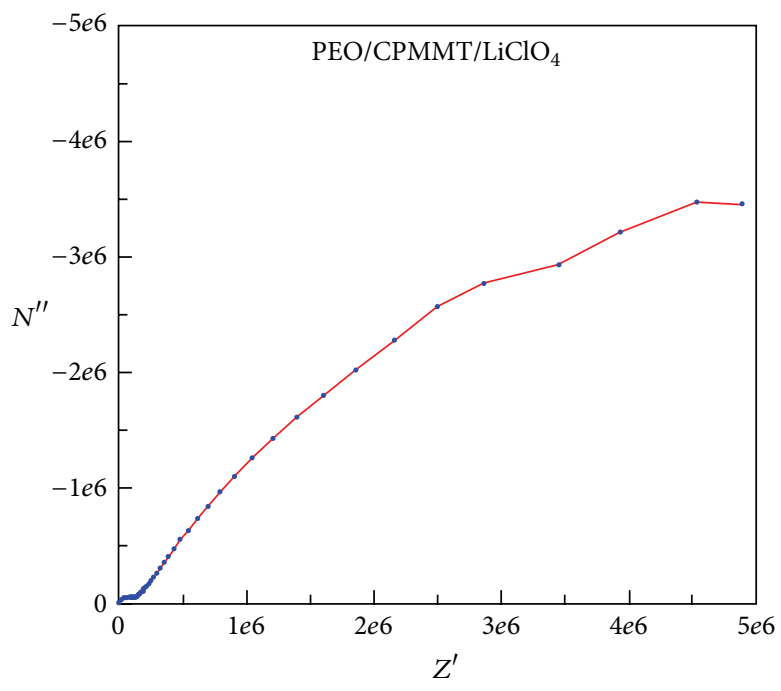

(c)

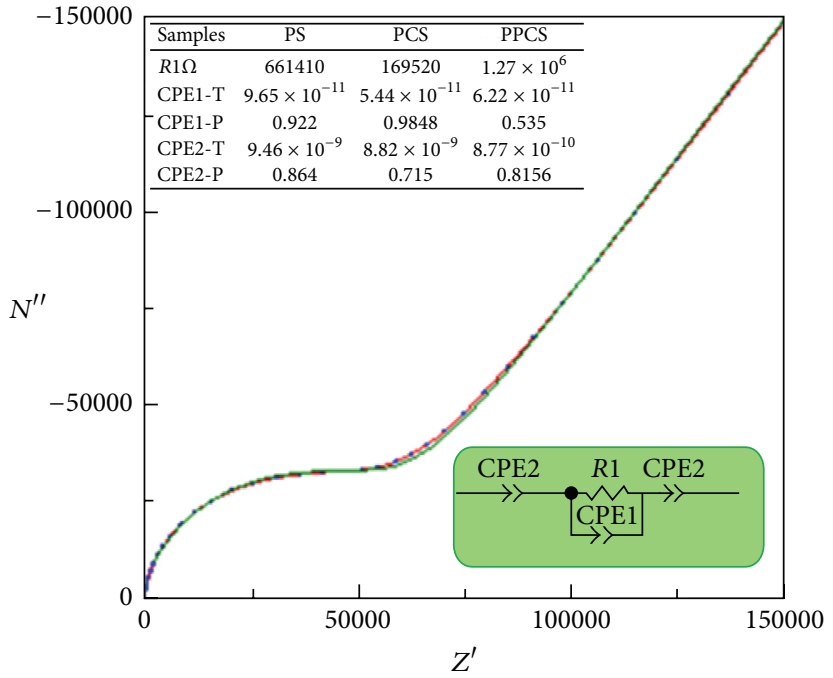

(b)

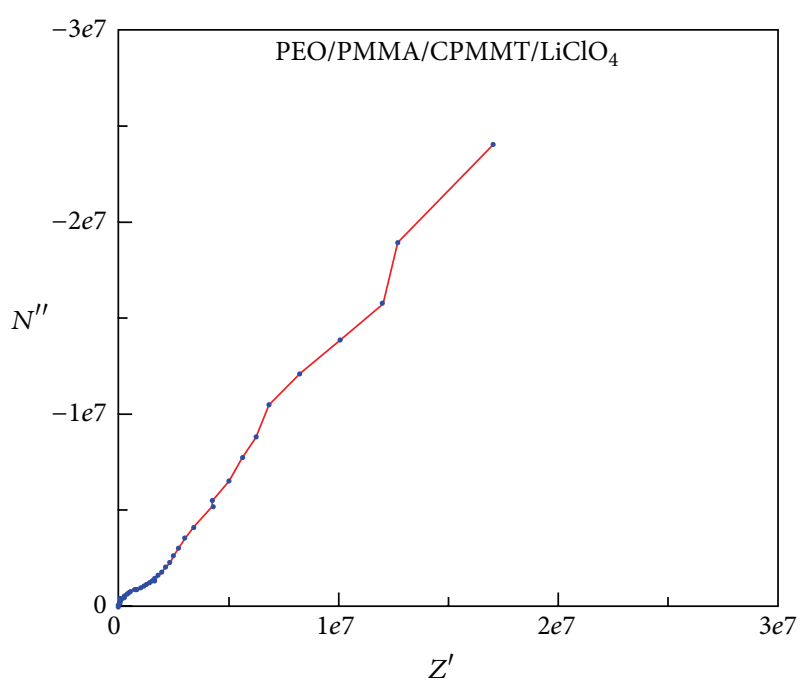

(d)

Figure 9: Typical Nyquist impedance plots for PEO/Salt (PS) (a), PEO/Salt (PS) after fitting to equivalent circuit (b). Inset showing that diagram of circuit and extracted parameters for the circuit elements of PS, PCS, and PPCS are summarized in the table. PEO/Salt/CPMMT (PCS) (c). PEO/PMMA/Salt/CPMMT (PPCS) (d).

PEO for solid polymer electrolyte (SPE) composites. From the values of ionic conductivity given in Figure 10 and inset table, it is clear that the addition of PMMA to PEO/Salt electrolyte system decreases the conductivity of PCS system but still shows higher value than pure PEO films. The rigid structure of PMMA due to the entrapped silicate layers alters the segmental dynamics of PEO so there is decrease in conductivity. Jeddi and coworkers [28] have reported an overlap weight fraction for PEO/PMMA blend which is about $2.8 \mathrm{wt} \%$ for PEO. Overlap weight fraction is that weight at which PEO starts interpenetration and miscibility of blends is affected. In our system the amount of PEO is far more than overlap weight fraction. So it causes decrease in conductivity and an increase in the agglomeration of clay by decreasing its interaction with the PEO. The same trend has been observed in mechanical properties of the PEO/PMMA/Salt/CPMMT (PPCS) composites. The values of ionic conductivity we reached at laboratory temperature of $15^{\circ} \mathrm{C}$ are higher than those reported for the PEO/PMMA/salt/Na-MMT in the literature at $25^{\circ} \mathrm{C}$ [22]. This increase may be caused by the better dispersion of CPMMT.

\subsection{Elongation at Break of $\mathrm{PEO} / \mathrm{LiClO}_{4} / \mathrm{CPMMT}$ Composite} System. Elongation at break is the strain at failure or percent change at failure and explains the ductility of the material with external force. The effect of salt addition on the ductility or \% elongation is shown in Figure 11. The result from Figure 11 depicts that ductility of the composite material increases with increasing salt concentration in the resulting composites. This increase is attributed to the presence of 


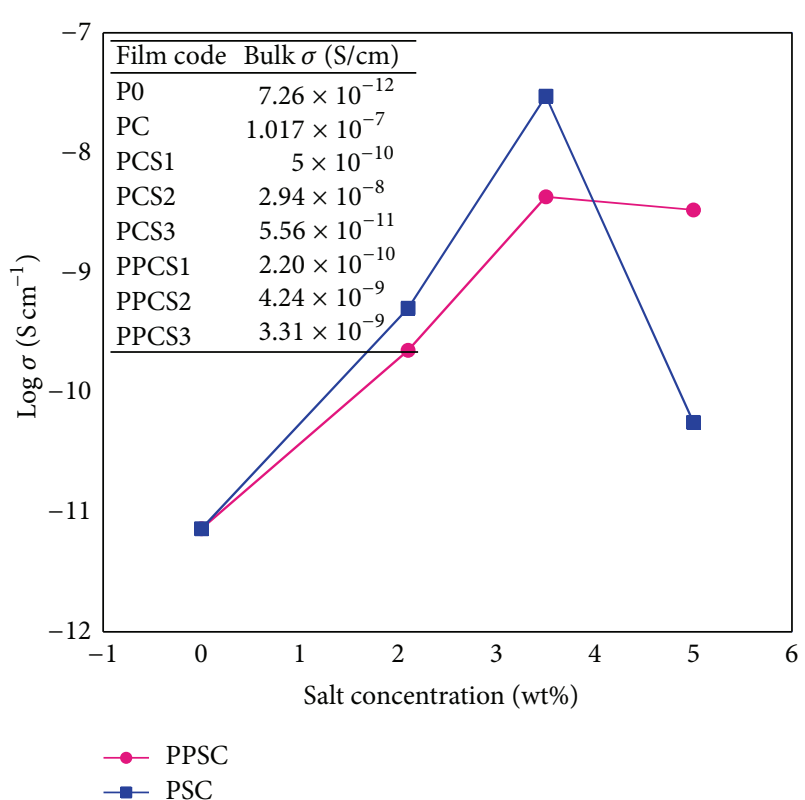

FIGURE 10: Bulk ionic conductivity variation for PSC and PPSC with weight $\%$ of salt for composite system at room temperature $\left(15^{\circ} \mathrm{C}\right)$.

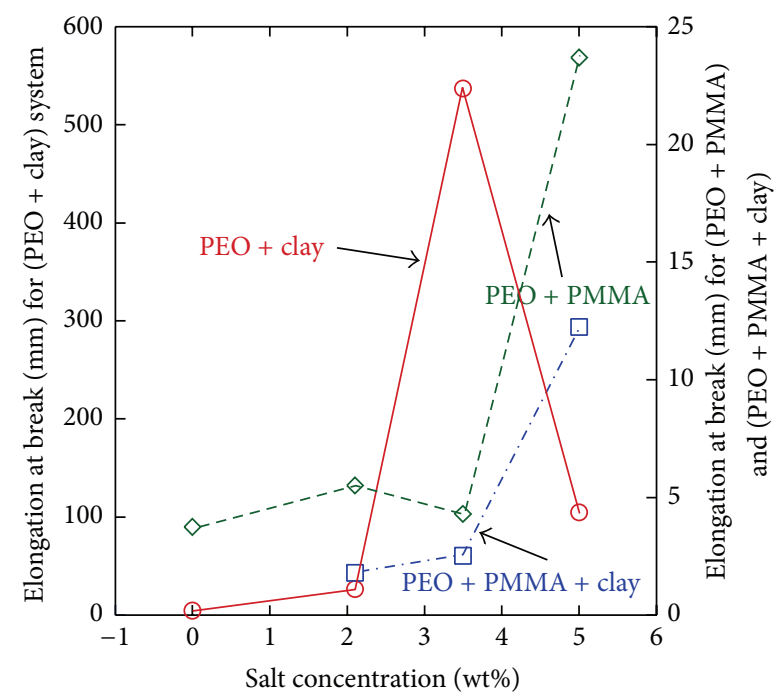

Figure 11: Variation of elongation at break for PEO/Clay (PC), $\mathrm{PEO} / \mathrm{PMMA}$, and PEO/PMMA/Clay (PPC) composite and blend composite system with varying content of salt.

CPMMT which enhances the mobility of the PEO polymer. The highest \% elongation at break is obtained for the PCS2 composite and beyond PCS2\% elongation at break decreases. The higher uniformity in the dispersion of salt and clay within PEO is correlated with better adhesion between the components of the composite due to the homogeneous dispersion of CPCMMT at PCS2 composition. The decrease in the ductility beyond PCS2 is due to the restriction in chain mobility of the matrix and the filler particles acting as defect points [29]. This also shows that beyond certain limit of salt concentration the behavior changes. Further, at higher

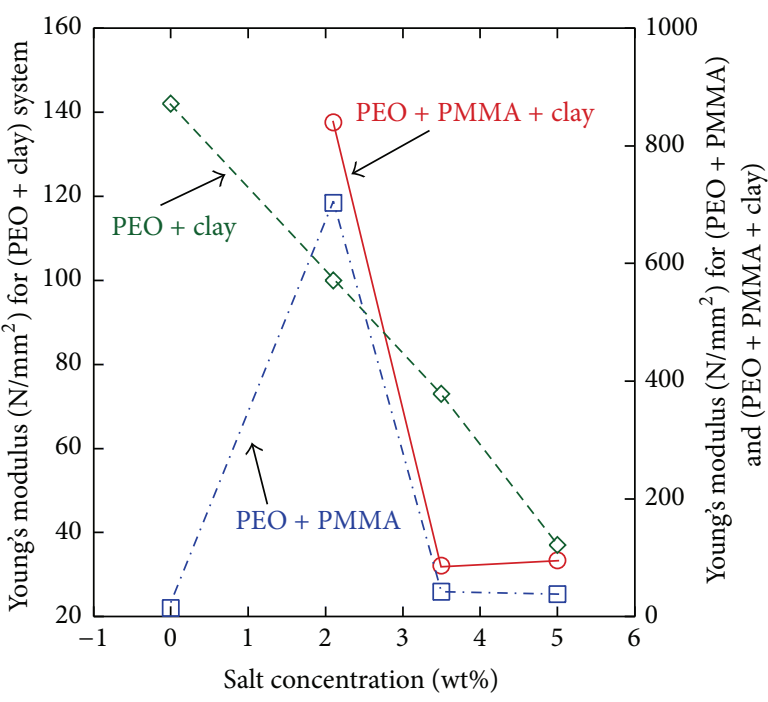

FIgURE 12: Variations of Young's modulus for PEO/Clay (PC), $\mathrm{PEO} / \mathrm{PMMA}$, and PEO/PMMA/Clay (PPC) composite and blend composite system with varying content of salt.

concentrations the polymers exist in agglomeration and the clay is not well dispersed. The overall result is the increase in the ductility of the composite material with increasing salt concentration. The net increase in elongation at break for PCS system suggests filler induced dimensional stability to the composite electrolyte films, making them capable of sustaining and withstanding any external pressure/shock to a better level.

3.6. Young's Modulus of PEO/LiClO $/ 4$ CPMMT Composites. Young's modulus is a variable that describes the relationship of stress to strain within the elastic region. This is measured from the slope of the curve within the elastic area of the specimen. The modulus of elasticity describes a material's stiffness; the greater the modulus, the stiffer the material. It quantifies the elasticity of the polymer.It is truly associated with primary and secondary chemical bonds. Unlike the neat polymer where the mechanical properties are determined almost entirely by matrix, the mechanical properties of the composite depend on the interaction between the polymer and the added fillers. From Figure 12 it is clear that Young's modulus of the composites electrolyte decreases with the increasing concentration of inorganic contents at constant clay level. The influence of $\mathrm{LiClO}_{4}$ on the mechanical properties of PEO/CPMMT film resembles the plasticization effect. The interaction between PEO and CPMMT is weakened by the increasing content of salt. The same behavior of Young's modulus with filler has been reported earlier in the literature [29]. As mechanical properties change by changing the composition of components as well as with the applied force, they are difficult to analyze. Also, this decrease may probably be explained in terms of debonding around polymer and clay interphases and void formation. It can be concluded that value of modulus depends highly on the distribution of filler particles in the polymer matrix, which in turn depends on 
the particle/particle interaction (agglomeration) and polymer particle interaction (adhesion and wetting) and morphology of the filler particles [30].

\subsection{Elongations at Break of PEO/PMMA/LiClO4/CPMMT} Blend Composites System. In order to have a more clear idea of the change in mechanical properties of the blend composite system, first the addition of salt to the blend system was studied for its effect on the mechanical properties and then CPMMT was added to the same system and the samples were analyzed by UTM. From the results given in Figure 11, it is clear that elongation at break decreases initially with the increasing concentration of salt to the blend system and then starts increasing with higher salt concentration. This decrease in failure strain is due to the rigid filler addition, which restricts the mobility of the PEO polymer molecules to flow freely past one another, thus causing premature failure. The original elasticity of PEO is distorted due to the addition of PMMA and $\mathrm{LiClO}_{4}$ which is in close agreement with the conclusion that the addition of rigid particles like PMMA into the polymer matrix increases its stiffness and toughness $[31,32]$. Composites with these properties can be used for heat resistant materials or product packaging materials.

\subsection{Young's Modulus of PEO/PMMA/LiClO $4 / C P M M$ Blend} Composites System. Young's modulus of the PEO/PMMA as a function of salt is shown in Figure 12. From this Figure it is clear that Young's modulus of the blend composite shows an overall decrease with the addition of salt. This decrease shows the weaker PEO interchain interaction and increase in the particle size of the inorganic phase because of local aggregations of particles in the presence of PMMA; these phenomena may act as flaws in it $[33,34]$. The same trend has been confirmed by the SEM result as well. This means that the addition of salt to the PEO/PMMA composite suppresses the material's stiffness and hence elasticity of the polymer. But when clay was added to the same PEO/PMMA/Salt system, an enormous increase in the value of Young modulus was observed as shown in Figure 12. This is due to the intercalation of polymer chains within the clay galleries that avoid segmental motion of the polymer chains [35]. Although there is an overall decrease in the value of Young modulus of the $\mathrm{PEO} / \mathrm{PMMA} / \mathrm{LiClO}_{4} / \mathrm{CPMMT}$ system with increasing salt concentration, still it is much higher than that of the virgin (neat) poly(ethylene oxide) (PEO) and PEO/Salt/CPMMT. This is in close agreement with the conclusion that the addition of rigid particles like PMMA into the polymer matrix increases its stiffness [31].

\section{Conclusions}

This work used cetylpyridinium chloride to modify MMT mixed with higher molecular weight $\mathrm{PEO} / \mathrm{LiClO}_{4}$ and $\mathrm{PEO} / \mathrm{PMMA}_{\mathrm{LiClO}}$ to produce composite materials. The experimental results showed that at constant salt content the addition of CPMMT first reduces crystallinity of PEO till $3.3 \mathrm{wt} \%$ of clay and then starts increasing at higher clay content. Thus $3.3 \mathrm{wt} \%$ of clay was selected as the optimum clay loadings for composites fabrication. The XRD results showed that the crystallinity of composites at optimum clay loading increases with increasing salt content and ionic conductivity obtained from impedance technique showed declining trend with higher salt content. The addition of $50 \mathrm{wt} \%$ of higher molecular weight PMMA to the composite of PEO/Salt/CPMMT affected the properties due to the immiscibility or aggregation of filler within the polymer matrix; however, the blend composites showed better mechanical performance. The composite of PEO with $3.5 \mathrm{wt} \%$ of salt and $3.3 \mathrm{wt} \%$ of CPMMT exhibited better performance.

\section{Conflict of Interests}

The authors declare that there is no conflict of interests regarding the publication of this paper.

\section{References}

[1] S. Sultana, Fabrication and studies on thin film composites of Poly (Ethylene Oxide) [Ph.D. thesis], University of Peshawar, Peshawar, Pakistan, 2013.

[2] T. Lan, P. D. Kaviratna, and T. J. Pinnavaia, "Epoxy selfpolymerization in smectite clays," Journal of Physics and Chemistry of Solids, vol. 57, no. 6-8, pp. 1005-1010, 1996.

[3] X. Q. Yang, H. S. Lee, L. Hanson, J. McBreen, and Y. Okamoto, "Development of a new plasticizer for poly(ethylene oxide)based polymer electrolyte and the investigation of their ion-pair dissociation effect," Journal of Power Sources, vol. 54, no. 2, pp. 198-204, 1995.

[4] R. Mishra and K. J. Rao, "Electrical conductivity studies of poly(ethyleneoxide)-poly(vinylalcohol) blends," Solid State Ionics, vol. 106, no. 1-2, pp. 113-127, 1998.

[5] M. S. Khan, A. Shakoor, and J. Nisar, "Conductance study of poly(ethylene oxide)- and poly(propylene oxide)-based polyelectrolytes," Ionics, vol. 16, no. 6, pp. 539-542, 2010.

[6] Z. Shen, G. P. Simon, and Y.-B. Cheng, "Comparison of solution intercalation and melt intercalation of polymer-clay nanocomposites," Polymer, vol. 43, no. 15, pp. 4251-4260, 2002.

[7] P. Aranda and E. Ruiz-Hitzky, "New polyelectrolyte materials based on smectite polyoxyethylene intercalation compounds," Acta Polymerica, vol. 45, no. 2, pp. 59-67, 1994.

[8] D. Ratna, S. Divekar, A. B. Samui, B. C. Chakraborty, and A. K. Banthia, "Poly(ethylene oxide)/clay nanocomposite: thermomechanical properties and morphology," Polymer, vol. 47, no. 11, pp. 4068-4074, 2006.

[9] D. Ratna, S. Divekar, S. Patchaiappan, A. B. Samui, and B. C. Chakraborty, "Poly(ethylene oxide)/clay nanocomposites for solid polymer electrolyte applications," Polymer International, vol. 56, no. 7, pp. 900-904, 2007.

[10] S. K. Lim, J. W. Kim, I. Chin, Y. K. Kwon, and H. J. Choi, "Preparation and interaction characteristics of organically modified montmorillonite nanocomposite with miscible polymer blend of poly(ethylene oxide) and poly(methyl methacrylate)," Chemistry of Materials, vol. 14, no. 5, pp. 1989-1994, 2002.

[11] Y. H. Hyun, S. T. Lim, H. J. Choi, and M. S. Jhon, "Rheology of poly(ethylene oxide)/organoclay nanocomposites," Macromolecules, vol. 34, no. 23, pp. 8084-8093, 2001. 
[12] H.-W. Chen, C.-Y. Chiu, and F.-C. Chang, "Conductivity enhancement mechanism of the poly(ethylene oxide)/modifiedclay/LiClO 4 systems," Journal of Polymer Science. Part B: Polymer Physics, vol. 40, no. 13, pp. 1342-1353, 2002.

[13] S. Sultana, M. S. Khan, and M. Humayun, "Preparation, morphology, and thermal and optical properties of thin films of ferric chloride/polyethylene oxide composites," Turkish Journal of Chemistry, vol. 36, no. 5, pp. 709-716, 2012.

[14] R. Baskaran, S. Selvasekarapandian, N. Kuwata, J. Kawamura, and T. Hattori, "Conductivity and thermal studies of blend polymer electrolytes based on PVAc-PMMA," Solid State Ionics, vol. 177 , no. 26-32, pp. 2679-2682, 2006.

[15] S. K. Lim, S. T. Lim, H. B. Kim, I. Chin, and H. J. Choi, "Preparation and physical characterization of polyepichlorohydrin elastomer/clay nanocomposites," Journal of Macromolecular Science Part B: Physics, vol. 42, no. 6, pp. 1197-1208, 2003.

[16] B. Chen and J. R. G. Evans, "Preferential intercalation in polymer-clay nanocomposites," Journal of Physical Chemistry B, vol. 108, no. 39, pp. 14986-14990, 2004.

[17] B. Kumar and L. G. Scanlon, "Polymer-ceramic composite electrolytes: conductivity and thermal history effects," Solid State Ionics, vol. 124, no. 3, pp. 239-254, 1999.

[18] J.-H. Chang, S. J. Kim, Y. L. Joo, and S. Im, "Poly(ethylene terephthalate) nanocomposites by in situ interlayer polymerization: the thermo-mechanical properties and morphology of the hybrid fibers," Polymer, vol. 45, no. 3, pp. 919-926, 2004.

[19] X. Qian, N. Gu, Z. Cheng, X. Yang, E. Wang, and S. Dong, "Impedance study of $(\mathrm{PEO})_{10} \mathrm{LiClO}_{4}-\mathrm{Al}_{2} \mathrm{O}_{3}$ composite polymer electrolyte with blocking electrodes," Electrochimica Acta, vol. 46, no. 12, pp. 1829-1836, 2001.

[20] G. J. Brug, A. L. G. Van den Eeden, M. Sluyters-Rehbach, and J. H. Sluyters, "The analysis of electrode impedances complicated by the presence of a constant phase element," Journal of Electroanalytical Chemistry and Interfacial Electrochemistry, vol. 176, no. 1-2, pp. 275-295, 1984.

[21] F. Bellucci, M. Valentino, T. Monetta et al., "Impedance spectroscopy of reactive polymers. 1," Journal of Polymer Science, Part B: Polymer Physics, vol. 32, no. 15, pp. 2519-2527, 1994.

[22] J. T. S. Irvine, D. C. Sinclair, and A. R. West, "Electroceramics: characterization by impedance spectroscopy," Advanced Materials, vol. 2, no. 3, pp. 132-138, 1990.

[23] K. V. Kumar and G. S. Sundari, "Conductivity studies of $\left(\mathrm{PEO}+\mathrm{KHCO}_{3}\right)$ solid electrolyte system and its application as an electrochemical cell," Journal of Engineering Science and Technology, vol. 5, no. 2, pp. 130-139, 2010.

[24] P. C. Srivastava, in Solid State Ionics: Materials and Applications, B. V. R. Chowdar, Ed., pp. 561-565, World Scientific, Singapore, 1992.

[25] S. Ibrahim and M. R. Johan, "Conductivity, thermal and neural network model nanocomposite solid polymer electrolyte system (PEO-LiPF6-EC-CNT)," International Journal of Electrochemical Science, vol. 6, no. 11, pp. 5565-5587, 2011.

[26] P. P. Chu, M. J. Reddy, and J. Tsai, "Structural and transport characteristics of polyethylene oxide/phenolic resin blend solid polymer electrolytes," Journal of Polymer Science, Part B: Polymer Physics, vol. 42, no. 21, pp. 3866-3875, 2004.

[27] H.-W. Chen, C.-Y. Chiu, and F.-C. Chang, "Conductivity enhancement mechanism of the poly(ethylene oxide)/modified-clay/LiClO ${ }_{4}$ systems," Journal of Polymer Science, Part B: Polymer Physics, vol. 40, no. 13, pp. 1342-1353, 2002.
[28] K. Jeddi, N. T. Qazvini, S. H. Jafari, and H. A. Khonakdar, "Enhanced ionic conductivity in PEO/PMMA glassy miscible blends: role of nano-confinement of minority component chains," Journal of Polymer Science Part B: Polymer Physics, vol. 48, no. 19, pp. 2065-2071, 2010.

[29] S. Ramesh and N. B. Khoo, "Conductivity, mechanical and thermal studies on poly(methyl methacrylate)-based polymer electrolytes complexed with lithium tetraborate and propylene carbonate," Journal of Materials Engineering and Performance, vol. 21, no. 1, pp. 89-94, 2012.

[30] F. Ali, Synthesis and characterization of polyimide/silica based nano-composites material [M.Phil Thesis], University of Peshawar, Peshawar, Pakistan, 2006.

[31] S. Bai, J. Chen, Z. Huang, and Z. Yu, "The role of the interfacial strength in glass bead filled HDPE," Journal of Materials Science Letters, vol. 19, no. 17, pp. 1587-1589, 2000.

[32] G. Nasar, Synthesis and characterization of poly (vinyl alcohol) composites [M.Phil thesis], University of Peshawar, Peshawar, Pakistan, 2008.

[33] A. Bandyopadhyay, M. de Sarkar, and A. K. Bhowmick, "Poly(vinyl alcohol)/silica hybrid nanocomposites by sol-gel technique: synthesis and properties," Journal of Materials Science, vol. 40, no. 19, pp. 5233-5241, 2005.

[34] H. B. Kim, J. S. Choi, C. H. Lee, S. T. Lim, M. S. Jhon, and H. J. Choi, "Polymer blend/organoclay nanocomposite with poly(ethylene oxide) and poly(methyl methacrylate)," European Polymer Journal, vol. 41, no. 4, pp. 679-685, 2005.

[35] R. L. Ledoux and J. L. White, "Infra red studies of hydrogen bonding interaction between kaolinite surfaces and intercalated potassium acetate, hydrazine, formamide and urea," Journal of Colloid and Interface Science, vol. 21, pp. 27-52, 1996. 

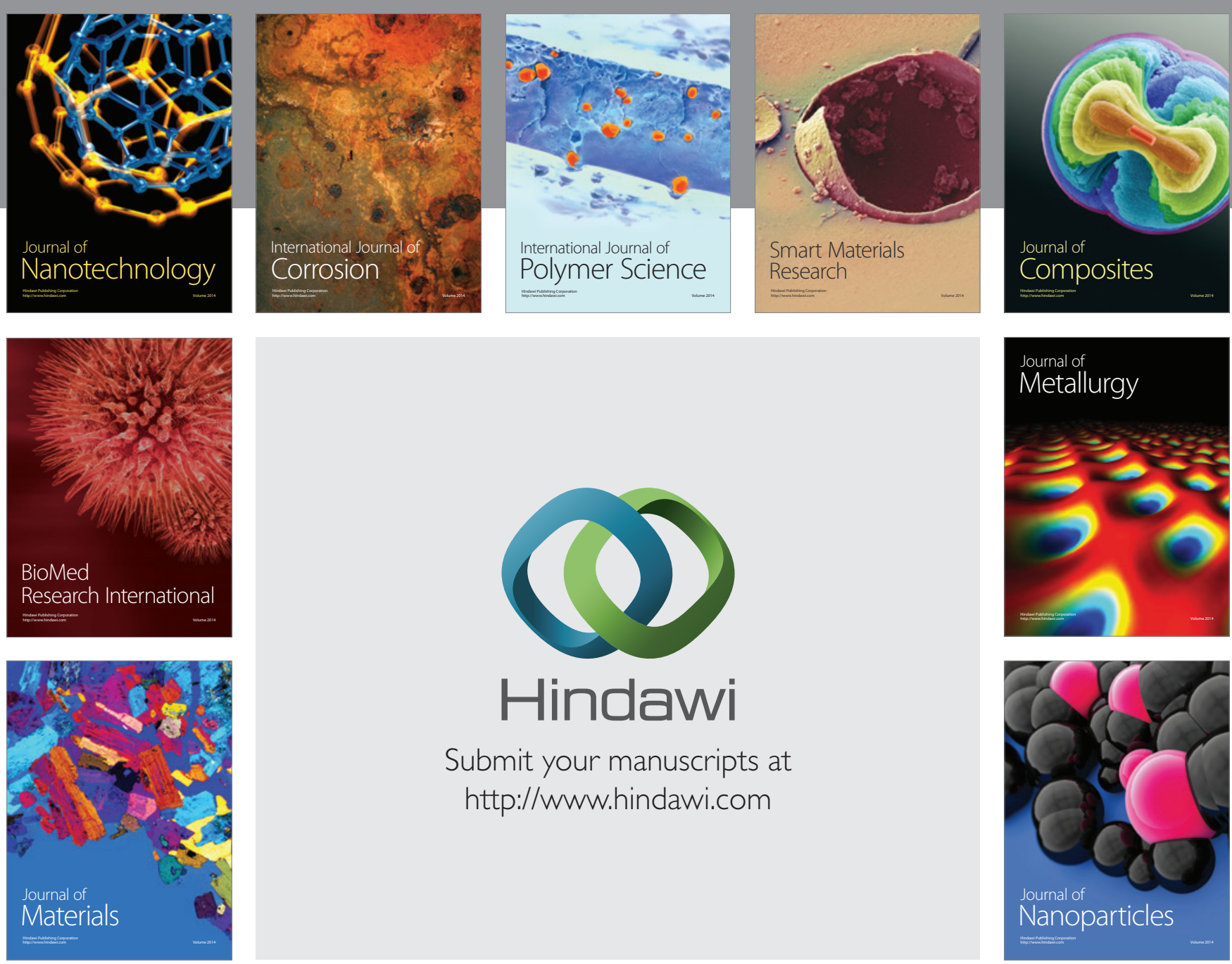

Submit your manuscripts at http://www.hindawi.com
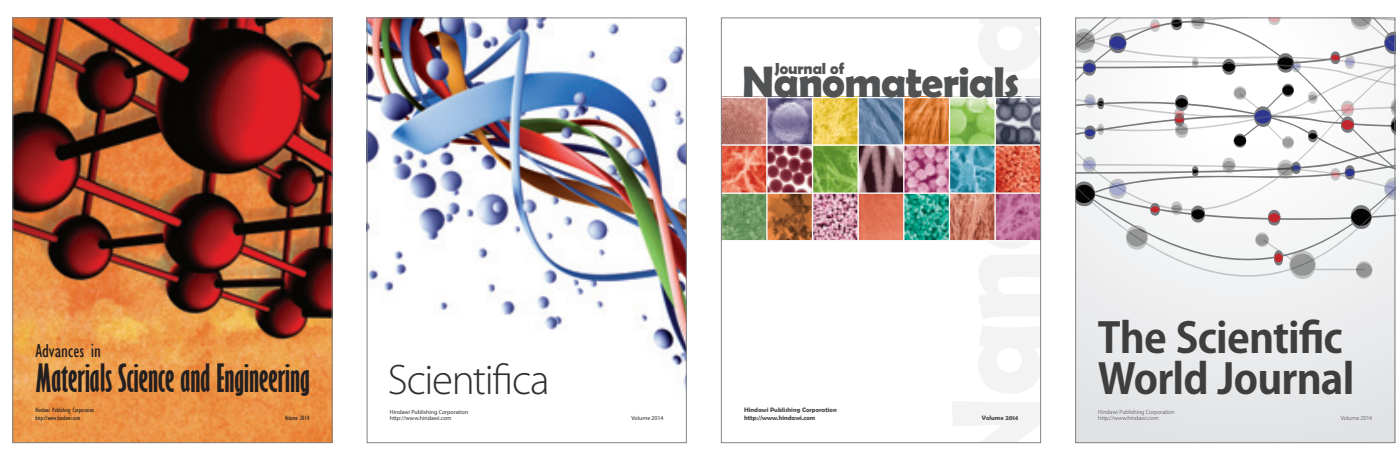

\section{The Scientific World Journal}
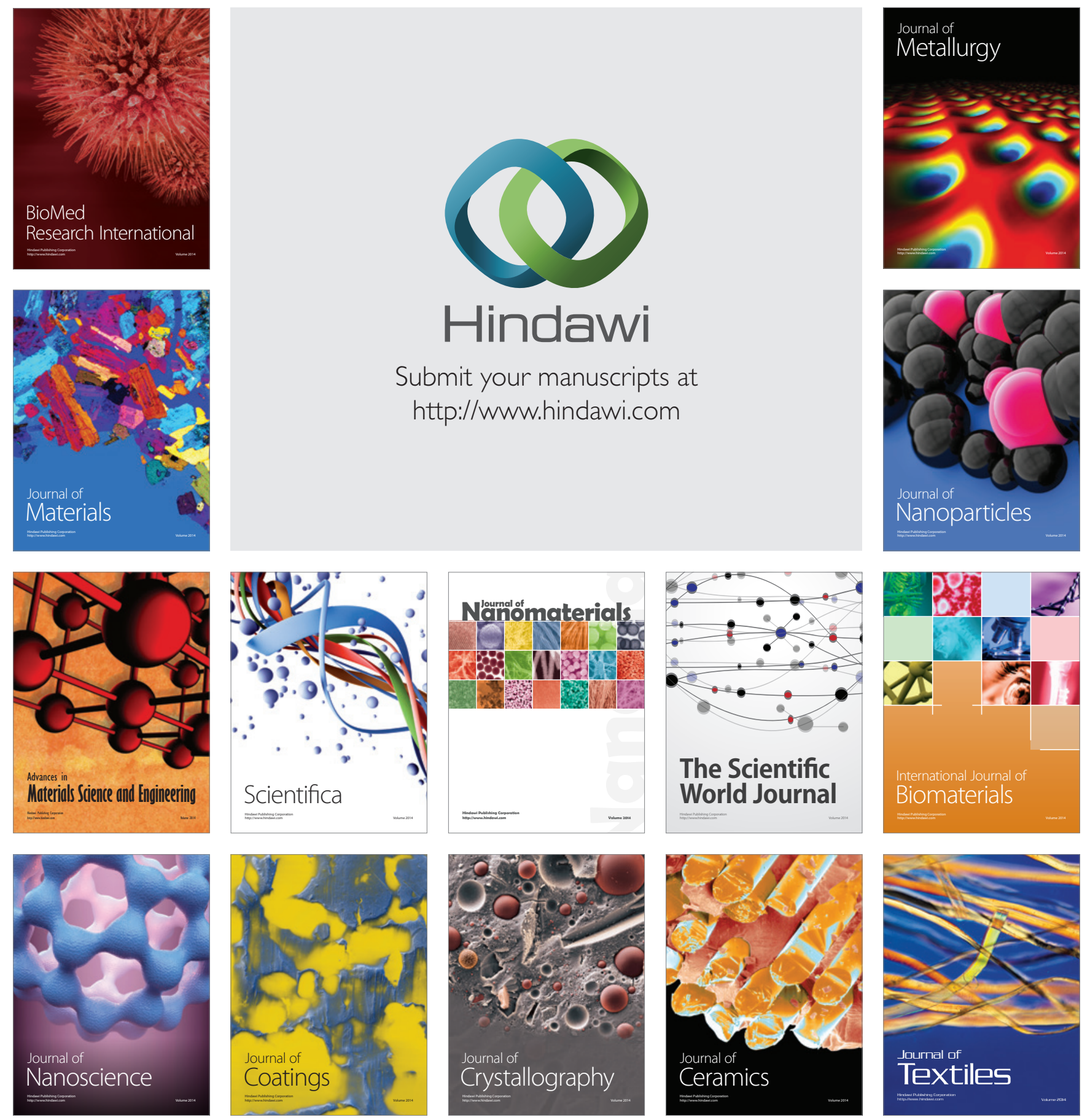